\title{
Visual Stimuli for Traumatic Memories: An Academic and Personal Memoir
}

\section{Vivien Green Fryd'}

\begin{abstract}
In this article, the author takes the subject-position as a survivor of father-daughter incest whose memories of her dissociated childhood traumatic experiences were triggered by viewing specific installations in the At Home:A Kentucky Project With Judy Chicago and Donald Woodman (2001-2002). The author shows how art functions as a ritualized site for witnessing trauma that can assist in individual recovery. She incorporated variety of trauma theories based on her scholarly understanding as well as personal experience of having experienced posttraumatic stress disorder.This study demonstrates that a viewer not only brings his or her own experiences and preknowledge to a work of art, thereby constructing its meaning, but that the work of art can act as a cue for the return of traumatic remembrance, becoming an agent on the viewer's emotional and personal journey.
\end{abstract}

\section{Keywords}

visual stimulus, traumatic memories, memories

Do I end my own silence? Do I admit in this public, scholarly space that I am a survivor who first recovered her memory of childhood sexual abuse when her daughter was 2 years old? Do I want to relive the trauma by writing about it and initiating the internal fear that I will be punished or shamed for doing so? Do I want you, a stranger, or perhaps a colleague, even a student or former student to know my "secret" about which I still feel shame and extreme anxiety? Will my public testimony about my childhood sexual trauma, which lasted roughly between the ages of 2 and 9 or 12, affect my family (especially my daughter, my brother who has asked me to not share my story, my nieces, and my nephew)? Will this influence your reading of my scholarly project? These are questions that I continually ponder as I write a book manuscript tentatively titled Representing and Performing Sexual Trauma in Second-Wave American Feminist Art. I had intended to include my personal narrative concerning how the viewing of a particular work of art triggered memories of my childhood sexual abuse, enabling me to remember who the perpetrator was after 9 years of my first memory and 5 years of intensive psychoanalysis. Art historians, however, clearly cannot accept this personal discourse, which is evident from the comments made by readers for a scholarly press. I thus decided to submit this personal memoir to another type of scholarly journal, one that exists for social workers, psychologists, and others who study trauma and provide treatment.

It is my hope that in ending my own silence, I can assist others and demonstrate how a work of art can act as a visual stimulus for memory retrieval. Although this is a difficult process for me, sometimes triggering emotional and physical symptoms of my own posttraumatic stress disorder (PTSD), I nevertheless take the subject-position as a survivor of father-daughter incest, whose memories of her dissociated childhood traumatic experiences were triggered by viewing specific installations in the At Home: A Kentucky Project With Judy Chicago and Donald Woodman (2001-2002) - in particular the Abuse Closet, Nightmare Nursery, and the Rape Garage. In this study, I show how art functions as a ritualized site for witnessing trauma that can assist in individual recovery. I incorporate a variety of trauma, theories based on my scholarly understanding as well as personal insights of having experienced PTSD. ${ }^{1}$ What I hope this study demonstrates is that a viewer not only brings his or her own experiences and preknowledge to a work of art, thereby constructing its meaning, but that the work of art can act as a cue for the return of traumatic remembrance, becoming an agent on the viewer's emotional and personal journey (Terr, 1994, pp. 12-13). ${ }^{2}$ In my case, the journey led from overwhelming and spinning thoughts, profound loneliness and sadness, depression, hypervigilance, shame, helplessness, hopelessness, prolonged distress, intense terror, anger,

\footnotetext{
'Vanderbilt University, Nashville, TN, USA
}

Corresponding Author:

Vivien Green Fryd, Department of History of Art, Vanderbilt University Email: vivien.g.fryd@vanderbilt.edu 
self-hatred, feeling like a "bad girl" and unsafe to remembering, accepting, and forgiving-although I occasionally re-experience some of these symptoms. I thus provide a dual reader response - an academic one, which assumes a distanced posture to sound objective, and a personal and emotional one, which recognizes that there is no such thing as a detached eye/I.

Bringing in a personal component is usually discouraged in the academic community. Art historians are expected to be detached and scholarly in their pursuits and conclusions, whereas artists are allowed, at least since the end of the 19th century, to express their emotions and personal responses to events. Genuine objectivity exists in no human voice, of course; the academic voice, too, is always personal, despite the positivistic and rhetorical posture that has passed as scientific for more than two centuries. This is acknowledged in so called "reader-response theory." "Reader-critics take the existence of the reader as a decisive component of any meaningful literary analysis," so that, in the words of Michael Riffaterre, "readers make the literary event" (Rabinowitz, 1994, p. 606). I am not unique in suggesting that art historians can replace "reader" with "viewer" to suggest that "viewers make the artistic event." Viewers bring their own experiences and interpretations to a work of art and each viewer's understanding may be similar to or different from someone else's. In other words, each viewer's understanding is personally, historically, socially, and culturally constructed.

This essay is thus written in two registers. There is the academic voice that analyzes images and texts in light of earlier artworks and within a historical and cultural context, a professional voice that I have used in the nearly 30 years of my life as an art historian and which does not dominate in this essay given its audience. Then there is the personal voice of a survivor of childhood incest who became an active participant in the second wave of feminism as an undergraduate and a graduate student during the 1970s and early 1980s. While an undergraduate, I majored in art history while Linda Nochlin wrote her groundbreaking essay, "Why Have There Been No Great Women Artists?" (1971), exploring, for the first time, the cultural and institutional barriers that prevented women from becoming professional artists, and while Judy Chicago completed The Dinner Party (1974-1979), a complex, monumental, collaborative, and multimedia installation that dealt with a variety of themes, such as inserting women into history and the construction of vaginal or central-core iconography to symbolize and celebrate femininity and female sexuality. I completed in 1977 a master's thesis on a woman artist, Romaine Brooks, with the intention of joining Chicago, Nochlin, and others in reinserting women into the history of art. During this time, I also participated in various consciousness-raising (CR) groups and "speak outs" where women publicly discussed that which had been silenced. CR became the prime educational and organizing program of the women's liberation movement. Intended to raise awareness and understanding of women's lives and concerns, CR groups underlined the idea that individual, "personal" injuries and frustrations were not unique but common among women - that is, "political." Although many CR groups during this time addressed rape, I focused instead on my anger toward my mother, my anxiety about relationships with men, my opinions about the status of women in our patriarchal society, and on my eating disorder (binge eating) not knowing that it was a symptom of PTSD nor having any memory of my childhood experiences. My interest in feminism and art history, in other words, existed at the beginning of my undergraduate and graduate education, so that it should not come as a surprise that I now study rape and incest in American art, the field that is my specialization. The intersection between the subject of this study and myself is autobiographical, another influence of feminism, which argues that "the personal is political."

I thus join the community of "soul-wounded" women who, Charlotte Pierce-Baker (2006) argues, found their voices through the "pedagogy of trauma" by speaking out and writing (p. 3). Like the visual, auditory, and written voices in the At Home Project and other texts, I acknowledge, condemn, and hopefully contribute to ending our culture's silence about, and hence, acceptance of sexual violence. My ability to explain this process occurred not while in psychoanalysis but afterward when I began reading about trauma studies and writing my personal narrative and scholarly art history book. What follows then is a memoir that combines art history and trauma studies.

\section{Viewing a Work of Art for a Lecture}

In the spring of 2002, I kept receiving e-mails that announced the impending close of the At Home Project. I teach Chicago's work in my Art Since 1945 lecture course every 2 years at Vanderbilt University, so I wanted to see this new project. I arrived in Bowling Green and approached what looked like a typical suburban home. A young man with a shaved head introduced himself as our tour guide. Little did I know that Joshua Edwards and I would engage in a series of conversations about this project, that the viewing of the installation would inspire me to write a chapter for a book I had just begun about rape in American art and that specific installations would cue the retrieval of traumatic remembrance.

When I first toured the exhibition, I thought my interest lay solely in updating my lecture on Chicago's feminist projects. I thus took copious notes and asked Edwards numerous questions, conceptualizing ideas for a lecture that would compare second-wave feminist concerns in Womanhouse to third-wave ones in the At Home Project. A total of 22 students in the Kentucky course created site installations in a reclaimed house that they renovated, revisiting the subject of the home as a domestic space that Chicago, along with Miriam Shapiro, had explored at the California Institute of 


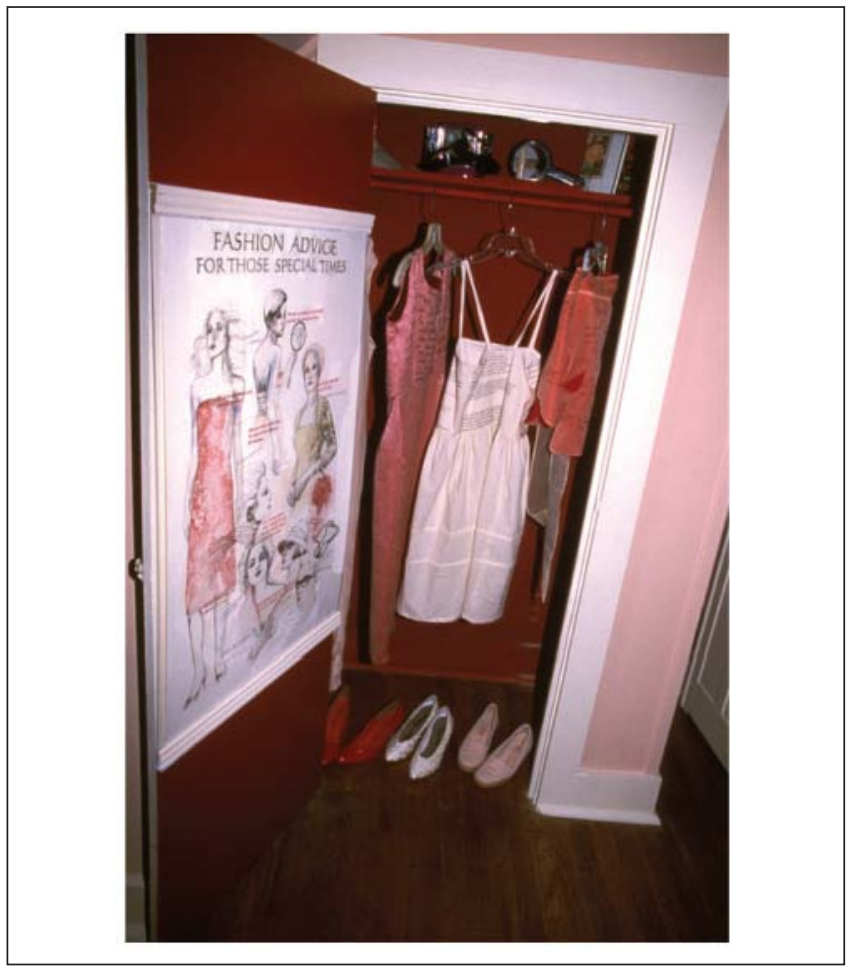

Figure I. Abuse Closet

the Arts in 1971. The 22 California Arts students cleaned, tore up, and rebuilt a dilapidated house (called Womanhouse), creating a series of site installations and performances that focused on the everyday life of an ordinary White middleclass housewife. The project incorporated such feminist concerns as nurturance, sexuality, marriage, pregnancy, and menstruation. Unlike Womanhouse, in which only women participated under the leadership of two female professorsChicago and Schapiro - the At Home Project involved male and female students, working with a male (Woodman) and a female (Chicago) artist/facilitator. Besides including the male voice, appropriate given the rise in the 1980s of the men's movement inspired by the second-wave feminist movement, the At Home Project incorporated other new and timely themes: eating disorders, television and our mediasaturated culture, aging, prejudices, pornography, male adolescence, male sibling rivalry, race, and the constructions of masculinity. The At Home Project significantly addressed three additional subjects that had not been included in the earlier Womanhouse: domestic violence in the Abuse Closet by Freda Fairchild (Figure 1); incest in Nightmare Nursery by Kevin Baker and Nancy Turner (Figure 2); and rape in Rape Garage by Stefanie Bruser, Josh Edwards, Katie Grone, and Lindsey Lee (Figure 3). Each installation represented, exposed, confronted, and criticized these forms of abuse, returning to similar concerns explored in the 1970s by West Coast feminist artists. These younger artists of the early 21 st century elaborated on the issues that their second-wave

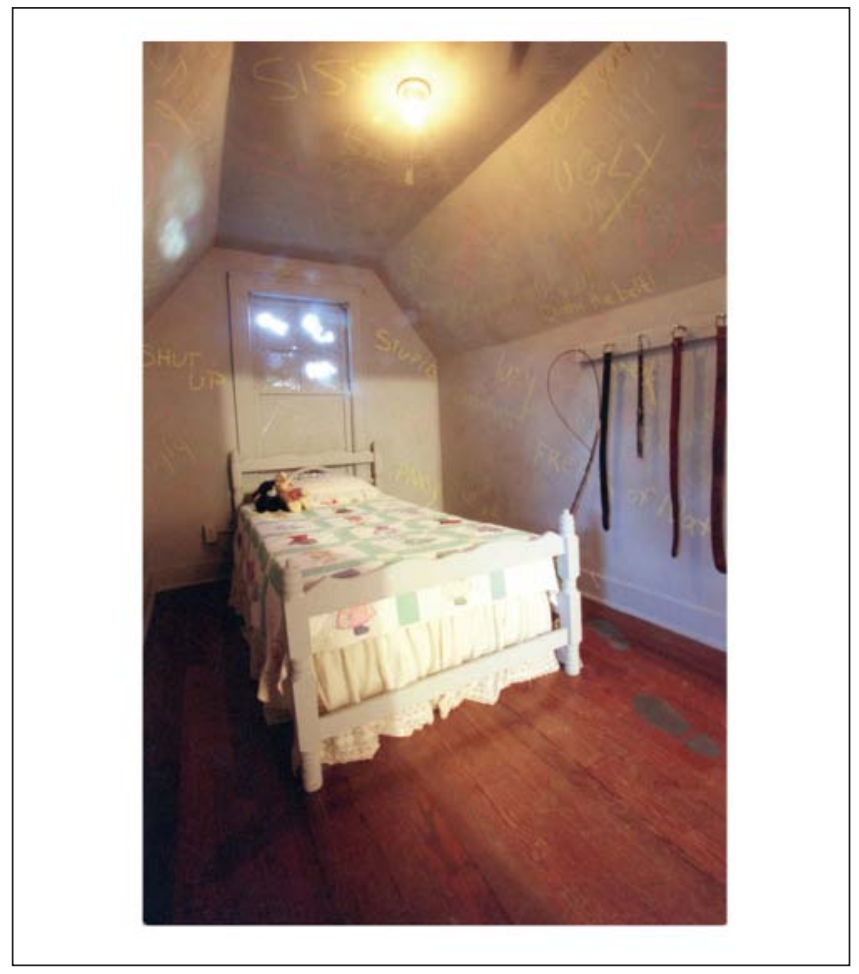

Figure 2. Nightmare Nursery

predecessors had addressed and included a new, third-wave lens, through which to study violence in American culture: violence against the male body. They revealed the underside of American domestic family life - violence and prejudiceshowing what resides in the garage, bedroom, and closet as the foundation of everyday American family life. These, at least, were my scholarly thoughts as I viewed the At Home Project, taking copious notes as I viewed each installation.

Before I elaborate on my personal responses to the installations, it is necessary to briefly describe these three rooms that dealt with sexual abuse because each triggered a memory. I first recognized that the Abuse Closet provided a topic for my project, for it clearly exposed and critiqued domestic violence. It contained fashionable pink, white, and deep-salmon dresses, shoes on the floor, and a poster on the inside of the open door. This Fashion Advice Poster by Diane Huff (Figure 4) represented fashion models sketched quickly in pencil outline with some modeling of the bodies and heads. On closer inspection, these beautiful models appeared bruised and battered, with black eyes, bruises on arms and necks, and broken ribs. Words in advertising type rationalized the damage: "It will never happen again," "He didn't mean it," and "I am so sorry, honey." One text on a dress hanging in the closet wondered: "He always wants me often he beats me at first I thought it was because he felt sorry. Could it be that he felt sorry? Could it be that the beating turns me on? He says it is not rape because I am his wife." 


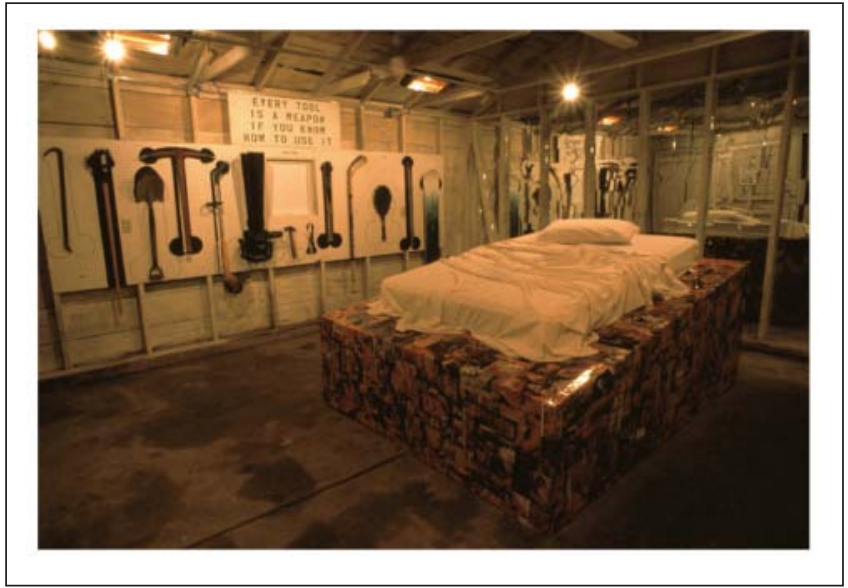

Figure 3. Rape Garage

I then went upstairs with my guide. Again I faced a room that immediately captured my attention as a potential topic for my studies: Nightmare Nursery. In this child's bedroom filled with a twin-sized bed and toys, words conveyed a sense of underlying angst despite the room's superficial tranquility. Scratched into the black paint that covered the windows were the phrases: "fear, stop, help me, Mommy!!!" and "alone, help, pain." The darkened windows blocked light and also viewing from the outside. This, along with a nightlight, suggested nighttime. Large blue footprints moved from the doorway to the child's bed, and a shadowed hand loomed above in the ceiling. Five belts and a strap hung on the wall, indicating the potential of domestic violence. Toy blocks on the floor spelled out the word "ugly," while scribbled words covered the walls: "shut up," "freak," "nerd," "dumbo," "stupid," "pansy," "ugly," "freak of nature."

After I finished taking notes about the inside installations, we walked outside the home to the garage. Josh warned me that it would be dark and would take some time to see clearly. As my eyes adjusted, I was excited, for I sensed that here was another space that clearly would apply to my new book: the Rape Garage. I immediately noticed six black and white photographs of the students who had worked on this installation and listened to the recorded narrations in which these same students detailed their personal experiences with rape. This included Josh Edward's photograph and his narration of his having been raped by a female, enabling me to enlarge my study of rape against the female body to also explore rape against the male body. In between the photographs were texts that provided information about domestic violence, incest, and rape in the United States.

Located in the center of this room was a bed. Placed on a tilted platform against a shattered mirror, this king-sized bed was covered with images from a multitude of pornographic magazines, forming a dizzying collage. One photograph on the bed completely absorbed me: a black and white pornographic picture from the 1950 s or 1960 s in which a man,

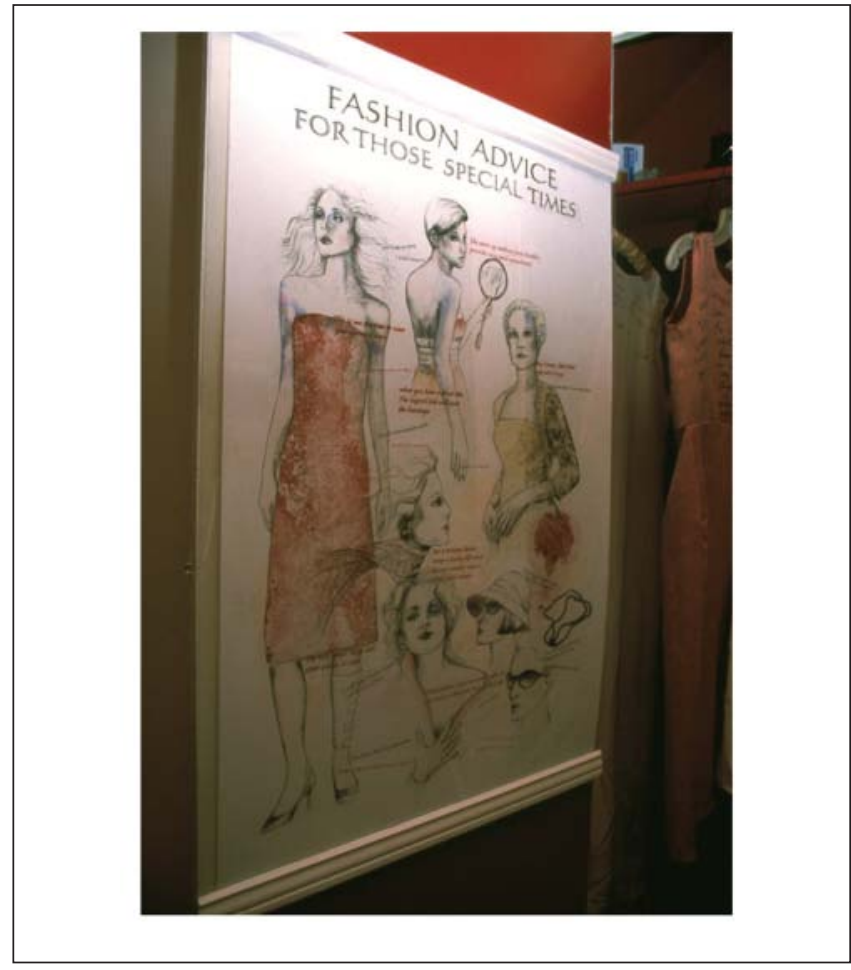

Figure 4. Fashion Advice Poster

seated on a lounge chair, grips the edge of his seat while a woman performs oral sex. Extreme fright took over: I felt anxiety in the pit of my stomach, nausea, and a vague sense that this image was triggering an emotional response. Did that response mean I was carrying the traces of an old memory? ${ }^{3}$ At this moment, I moved in my thought processes from the scholarly voice to a more personal one.

\section{Visual Cues for the Recovery of Traumatic Memories}

Before explaining how the Abuse Closet, Nightmare Nursery, and Rape Garage functioned as visual stimuli for traumatic remembrance, I need to provide some autobiographical and personal information, which is difficult for me. As mentioned above, I had had my first memory of having been sexually abused in 1993 when my daughter was 2 years old. This occurred while watching a Hollywood romantic comedy one evening with my former husband and my mother, realizing that I was feeling increasingly agitated and uncomfortable. When we finished the movie and my mother went to bed, I burst out sobbing. I did not remember anything specific, but I had a vague sense that something of a sexual nature had happened to me when I was a child. Over time, this spontaneous memory return resulted in increased depression, suicidal thoughts, intense fear, sleep problems, and binge eating. I went into therapy for a 3-year period. Other issues (especially my mom's diagnosis of Alzheimer's and marital problems), 
however, interfered with my goal of remembering and coming to terms with my past. Three years later, I began psychoanalysis with Dr. C., which lasted for 7 years. Following Freudian analysis, Dr. C. sat behind me while I lay on a couch, projecting my thoughts which he occasionally commented on and analyzed. Dr. C. allowed other types of analysis to occur, depending on where I was in the therapy and what he or I thought would be helpful. For example, toward the end of therapy and after I remembered who the perpetrator had been, I brought a sledge hammer and photographs of him, which I placed in a circle around a ceramic bust portrait of a man. In a rage, I destroyed the bust into tiny fragments, transferring my anger onto this sculpture.

I visited the At Home Project during my fifth year in psychoanalysis with Dr. C. At that time, I remembered more clearly that some man (or a variety of men) had entered my room late at night while I was in a deep sleep, had tapped me on the shoulder to wake me up, and had performed sexual acts with me. But I still could not fully recover who the perpetrator was. Later that afternoon after viewing the At Home Project and while talking to my psychoanalyst, I became increasingly upset and frightened while attempting to describe the one particular image in the Rape Garage that I found disturbing. As I talked about the photograph, I could not remember what it represented, a curious forgetting given my career as an art historian. I pondered why this particular image, which I could not describe, amidst the dozens of pornographic representations, captured my attention. As I talked with Dr. C., I realized that my neck began to hurt even though no one, including myself, was touching it. I felt as if I was being strangled and was having difficulty breathing.

When I began to describe the Nightmare Nursery to my therapist, I realized that the words "alone," "help," "pain," "Mommy!!!," "Stop," "Help Me," and "Fear" were my words. As a youngster, I said similar words either aloud or to myself while someone had forced me to engage in sexual activities. I also became nervous while describing to my analyst the large blue footsteps that led from the door to the bed and the enormous hand that dominated the ceiling, but I did not fully understand why. Something already registered and stored was blocked, and only emotional behaviors and body indicators suggested the beginning of a memory that remained hazy and fragmented. I decided to return to the $A t$ Home Project the next day with my laptop computer and write down my responses on seeing these installations again.

I first revisited the Rape Garage. Given my visually oriented profession, I was amazed at the difficulty I experienced in finding the one photograph to which I had had such a visceral response. Once I found it again, I was more in touch with my feelings: upset, terrified, anxious, and nauseated. But I still could not remember anything that would explain why this image triggered such a strong emotional response.

I then returned to the Nightmare Nursery. Stream of consciousness thoughts flowed onto my computer screen as I wrote in my laptop diary while in the room. I first noticed the word "ugly" in blocks on the floor and remembered the numerous times my mother had told me that I was fat and ugly. One of the more memorable events occurred while I participated during my senior year in high school in a state cheerleading contest. Our team came in second. My mother informed me that we placed second because my overweight body adversely affected our performance. I consequently quit the squad, never informing any of my schoolmates of the reason why. This had always been stored in my memory, as had the other times my mother said similar things. My relationship with my mother, although problematic, was relatively easy to discuss in therapy, for I remembered almost everything that had occurred with her (including her threats to commit suicide when I was a teenager). Although I felt extreme anger, I understood clearly why I responded this way to her.

While in the Nightmare Nursery this second time, I began to focus on the footsteps that led to the bed and realized I was getting increasingly nervous and afraid. I envisioned myself lying on the bed and being woken up from a deep sleep, seeing a man looming over me, holding me down with his hands on my shoulders, and pressing against me. At first I thought this was a game that my father had played with me when I was younger, pushing my shoulders up and down while I lay prone on my bed. But as I remembered this activity that I considered playful (about which now I wonder whether some sexual component existed), I realized that an overwhelming sense of fear resided in my stomach. I pondered, while writing in my computer, why I made a connection between my father, the footsteps painted in the room, this childhood game, and this room of childhood sexual abuse with the words on the window: "Fear, Stop, Help Me Mommy!!!" As I sat looking at the room and especially reading the words, my stomach got knotted up even more; I realized that this room was making me more and more upset. Although I had previously thought strangers had entered my bedroom at night to rape me, I remembered all of a sudden that the feet and hand looming over the bed belonged to my father. While this memory returned, my neck hurt, I felt terrified, and a range of thoughts entered my mind:

Help me. Someone help me. Stop this. Someone tell him to stop! I hate it. I can't stand this. I want to die. I hate you. I hate you. I want to scream. Someone is gripping my neck and it hurts so much. I can't breath. Someone help me. Someone has to help me. Stop! Please stop. Please help me.

I then burst out crying, left the room, and drove home.

What I realized afterward was that the traces of footsteps into the Nightmare Nursery triggered my memory that my father walked this path. I also suddenly realized that the man 
with short haircut, white T-shirt, and innocuous pants in the black and white photograph on the bed in The Rape Garage reminded me of my father! Only while writing the chapter about the At Home Project during the fall of 2003, however, did I realize that the Abuse Closet also enabled me to understand some aftereffects of incest. While enthusiastically informing my therapist that I had completed the chapter in the book about the At Home Project, I could not remember what I had written that morning about the Abuse Closet, an installation that had failed to trigger any responses when I first viewed it the previous year. My inability to remember always indicates that the topic is an important one for my recovery. As I reread the text from the installation- "It will never happen again," "I didn't mean it," "I am so sorry"-I wondered whether my mother or father said those words to me at some point. Did my father promise that he would stop? Did my mother, when she met me in the bathroom to clean me up after an interaction with my father (a memory that I recovered), say that she was sorry? Did my father ever say that he was sorry? Did he ever say that he didn't mean to hurt me, violate me, rape me? Of course not, for this would acknowledge what was happening. Silence-refusal to name what is taking place within the family-was necessary. When I told a family member, I was strangled. I learned my lesson then. Speaking out about the sexual violation could result in injury, even death, for I blacked out for a period of time when this happened. Thus the intense pain in my neck when I talked to Dr. C. about the disturbing photograph that I viewed in the Rape Garage probably was a bodily response to this memory.

Other texts from the installation seemed to resonate with me: "He always wants me often he beats me at first I thought it was because he felt sorry. Could it be that he felt sorry? Could it be that the beating turned me on? He says it is not rape because I am his wife." Is it my mother or father talking to me after strangling me? Is it my father after forcing me to perform some type of sexual act? Is it not rape because he could do anything he wanted as the patriarch of the family? Is it not rape because I helped my sick father who had multiple sclerosis feel better, as he told me each time? These are still unknowns to me, and because my parents are no longer alive, I am unable to ask. I doubt that they would have acknowledged the family secret even if I were to ask.

\section{Traumatic Memories}

If anyone prior to 1993 had informed me that I would undertake this journey of alternately remembering and forgetting (I literally could not hear my therapist sometimes when he said something that I found disturbing and often could not remember what we had discussed in a previous session), I would not have believed it. Although I had struggled with depression and eating disorders much of my life, I had no idea that its roots lay in the trauma of childhood sexual abuse. I had no memory of this. I would soon learn, however, that the residue of childhood sexual abuse has lasted my lifetime, leaving symptoms and signs that I have spent the past 16 years trying to recover and decipher. Some still remain vague and incomplete. In other words, I am a person who not only read about PTSD, but actually experienced it—still an amazing fact for me to process.

Now I understand the ways in which my trauma affects my memory. Neuroscientists have learned that during a trauma, the amygdala, which controls many of the physical responses, associated with fear and modulates memory formation, is triggered. Current models of amygdala functioning suggest that the amygdala can be activated by stimuli that are presented outside conscious awareness due to a subcortical pathway that bypasses the cortex (and hence precedes or occurs without conscious awareness of the stimuli). In such cases, the amygdala may trigger autonomic (somatic) responses of fear even in the absence of a complete awareness of the triggering stimuli or an explicit declarative memory of the earlier traumatic event. This sort of physical response ("physical memory") may thus occur in the absence of an ability to fully verbalize the source of the fear or the details of the earlier trauma. Research also shows that chronic exposures to trauma as a child may create a "kindling" effect so that the circuits become more easily triggered when exposed to a later trauma (Kaplan, 2005, pp. 37-38; Leys, 2000, pp. 256-260; McNally, 2003, pp. 62-66; Smith, Abou-Khali, \& Zald, 2009). In other words, there is a biological reason for my inability to learn as a child, remember the sexual abuse until relatively recently, and remember who tried to strangle me. And there is a reason I cannot remember much about my childhood at home before the age of 9; as Terr explains, "Children who experience Type II traumas ... may forget whole segments of childhood - from birth to age 9, for instance" (Terr, 1991, p. 16).

I now understand why, when my former husband used to come into the bedroom at night when I was asleep, I would sometimes wake up frantically screaming and sometimes try to jump out a window. My father used to wake me up at night by tapping me on the shoulder and then raping me. I now realize why I was an unhappy person who cried in secret places, why I binged, why I often felt afraid, estranged from others, and unloved, and why I had trouble learning before fourth grade. I also now understand that difficulty falling asleep, hypervigilance, "exaggerated startle response," marital conflict, rage, and feelings of "shame, despair," "hopelessness, being permanently damaged," lack of safety, helplessness, and "intense fear"-all experiences that I have felt throughout my life and occasionally still feel — constitute PTSD (American Psychiatric Association, 2000, pp. 463467). As Pat Ogden, Kekuni Minton, and Clare Pain (2006) summarize: "Through nonverbal remembering triggered by reminders of the event, traumatized individuals relive the emotional tenor of previous traumatic experiences, finding 
themselves at the mercy of intense trauma-related emotions" (p. 11). This is something I still experience when something triggers a memory of my original trauma, or when I "speak out," resulting in emotional and bodily responses.

I now know why I sometimes feel as if I am choking and as if I am going to black out. I always knew that my neck triggered intense reactions if it was touched. If my former husband stroked me there, no matter how tenderly, I panicked. Once when my then 3-year-old daughter accidentally grazed my neck while sitting on my lap during a movie, I became hysterical. I recognized that my daughter's touch failed to warrant such a strong, irrational response, and I surmised that I must be reacting to some past event involving an unknown person, but I could not remember that event. It was not until 9 years after my emotional response to my daughter's touch, and more than a year after seeing the At Home Project, that I allowed myself to remember that my mother or father (I still cannot remember which one) had strangled me in a fit of anger because I had revealed my "secret" to another family member. I had passed out. I remembered this after 1 month, during the summer of 2003, of agonizing, continual pain in my neck, a physical reaction as if a person's hand was constantly pressing against my Adam's apple, strangling me. I experienced difficulty breathing and at times began to black out. I knew that this physical pain was caused by emotions and memories, but my intellectualizing the process did not affect the concrete physical manifestations, which included a red mark that occasionally appeared on my neck during therapy when I felt this discomfort. Fortunately, my therapist served as a witness to my traumatic memories, blackouts, and the appearance of the red mark on my neck, confirming that I was not imagining them. Not getting back the memory of who choked me was a choice that Dr. C. and I made - a decision not to strain for a memory that would not automatically come and thus a deliberate decision not to develop a false memory. The choking memory remains fragmentary. Dr. C. also never reminded me until I viewed the $A t$ Home Project and claimed to remember for the first time that my father was the perpetrator that I had told him this the previous year. This further attests that he never planted false memories nor forced me to discuss something until I felt ready.

Lenore C. Terr, MD, a psychiatrist who specializes in childhood traumas and memory, identifies Type II trauma victims as those who repress their memories as a result of multiple experiences with trauma. She argues that when an individual encounters a cue, a perception that triggers an old, lost memory, the repression may break; in fact, she cites perceptual stimulus as the most effective means of memory retrieval, followed by dreams and the age of the adult traumasurvivor's child ("having children is a potent cue to one's own childhood memories"; Terr, 1994, p. 231). Both visual cues and my daughter's infancy triggered my recovery of repressed memories. Watching the Hollywood film, a visual cue when my daughter was 2 years (my child's "age had acted as a memory cue") triggered my first repressed memory (Terr, 1994, p. 128). Viewing specific rooms in the At Home Project (combined with years of psychotherapy) enabled the retrieval of multiple experiences with trauma and my most difficult repressed memory: my incestuous relationship with my father.

Terr (1994) explains that through repeated traumas, children learn to anticipate, suppress, and automatically repress; anticipation, in other words, encourages defensive memory loss during which a child can find some way to remove her anticipated agonies from her mind. Terr continues,

Childhood incest is one of the most difficult traumas for adults to remember. Incest feels particularly shameful. It engenders tremendous loyalty conflicts. And it can be anticipated. The young victim knows another incestuous episode is going to happen. The perpetrator, after all, has continual access to the child. So the child anticipates. (p. 131)

She elsewhere explains that the child experiences "intense surprise" but also "prolonged and sickening anticipation." (Terr, 1991, p. 11). I thus repeated a mental mantra when my father visited my room at night: I can do this, I'm ok, it will soon be over, just hang in there, please help me, I'm ok, I can do this, it will end soon, I'm O.K., I'm O.K.., I'm O.K.. I figured this out while in psychoanalysis. During the times when fragments of the abuse faded in and out of my memory while lying on the couch, I repeated these words out loud to my therapist and remembered reciting these words in my mind as a child. While lying on the couch, I also expressed intense surprise and prolonged and sickening anticipation. Often, when my therapist suddenly moved, I would panic, anticipating him to be a sexual predator. I reenacted my childhood experiences and transferred the fear of my father onto my analyst.

Traumatized children can also disassociate, which blocks retrieval, resulting in fuzzy, unclear recollections or a series of holes and fragments in memory (Terr, 1994, p. 87). Put another way, as James Chu (1998) explains "The biphasic pattern is the result of dissociation: traumatic events are distanced and dissociated from usual conscious awareness in the numbing phase, only to return in the intrusive phase" (p. 33). In the words of Applefield (1994), "In the intrusive phase, the person is plagued by unintegrated fragments of traumatic memories that return unbidden" whereas "in the numbing phase, these symptoms are kept at bay, but the individual feels numb and detached" (p. 18). Disassociation, "a mechanism that enables a person to quit a place [mentally] where bad thoughts or events are happening," often results from self-hypnosis: counting or repeating certain phrases over and over (Terr, 1994, pp. 77-78). This is clearly what I had done both as a child, silently repeating the passage cited above about being o.k. 
An incest survivor may also use a technique that Freud called Ich-Spaltung ("I-Splitting"). Within this context, dissociation may also make the trauma victim a spectator of his or her own experience as he or she moves (mentally) onto the ceiling or into an open closet and watches himself or herself. This is a "split" of the self into doer and watcher, but it combines with dissociation as well. I do not remember splitting as a child when the events took place, but I definitely split while in therapy, feeling as if I was watching fragmented film stills when I recovered fragments of my traumatic memories.

"I-Splitting" also occurs when a child is divided between two different personas: for example, a happy day-child and a terrified night-child (Terr, 1994, p. 124). My childhood was divided both between day and night and between summer camp and the school year. During the day, while in school, I was a normal child, or so I and everyone thought. I woke up in the morning, got dressed, ate breakfast, and went to school, although I had trouble learning. I could not learn the days of the week, how to tell time, how to add, subtract, or multiply. (Terr explains that short-term gaps often exist in learning when children dissociate along with splitting; Terr, 1994, pp. 126-127.) I followed the rules and never got into trouble. I played with kids in the neighborhood (this is according to my brother, for I have few memories of my childhood before the age of 9). I was Vivacious Vivien or, according to another nickname, Garrulous Green. I came from what I and others perceived as a normal middle-class suburban family, living on Long Island, New York, and then in Toms River, New Jersey.

During the summers, beginning at the age of 6 , I attended an 8-week sleepaway camp (Camp Lohikan on Lake Como in Pennsylvania). There I went horseback riding, swimming, hiking, camping, canoeing, and so on. I loved my time at camp and, in fact, as a young child thought these 8 weeks were the equivalent of the school year. At the end of camp, we always sang a song: "Three (or two, or one) more days of vacation, then we go to the station, back to civilization, I want to go home!" I always changed the words to "I don't want to go home," but I did not understand why. I amazingly remember every experience at camp, including my first day there with vivid details like bringing green grapes and a sailor's cap from home to give to my brother, who was already there. I remember little of my childhood during the school year.

The nighttime while at home was different. This was my other life. This was when my father came into my room, woke me up by touching my shoulder, and did things to me that I did not understand, but I knew I hated. I considered them "yucky." The nighttime was when my father told me that I was so beautiful he could not help himself. The nighttime was when my father told me that I had to do things with him so that he would feel better. The nighttime was when I repeated the mantra to myself and when my mother sometimes met me in the bathroom and cleaned me up, telling me that this is what little girls had to do. Alternatively, the nighttime was when my mother told me that I was a bad girl, but I was confused about why I was bad when I was being a good girl, doing what my father demanded and expected. The nighttime was when either my mother or my father choked me; I could not breathe, blacked out, and felt as if I was dying. The nighttime away from camp was when I felt unsafe, when no one protected me, when I was repeatedly raped by my father and felt revulsion, fear, confusion, and helplessness.

Now I finally can go to sleep most nights and wake up most mornings without a pit in my stomach, although sometimes the fear returns, especially after I speak publicly about my trauma or while writing and revising this memoir. Now I know when I am feeling intense terror that I am nevertheless safe in my own bedroom and home. Now I know when my neck hurts and I cannot breathe that this is a memory of a childhood trauma. I now accept that this piece of the memory that I cannot recover-who strangled me-may never fall into place. Now I understand one reason why I became an academic; intellectual thinking enabled me to disassociate from my feelings and my body. Now the refrain of "bad girl, bad girl," seldom resonates in my mind. Now I know that I was not responsible for what happened, that I did not ask for "it" (which is how I as a presexual child understood the acts), and that my father was the perpetrator who failed to protect me, love me in a healthy, nonsexual manner, and comfort me. Now I think I understand why my mother consistently informed me that I was fat and ugly and that she was more beautiful than me-she felt in competition with me for my father's sexual attention. Now I realize that the only way I was able to survive as a child was to dissociate while "it" took place - to "achieve self-removal"- — so as not to remember, and that the habit of not telling, which was forced on me, "moves toward suppression of thought and eventually to repression" as a means to "block their retrieval" (Terr, 1994, pp. 46,51 , and 88 ). Now the night and day are no longer two different lives but one. Now the little girl remembers and realizes most of the time that she is safe. Now the little girl and the adult woman have merged. Now we remember and no longer remain silent.

Now I understand that certain images can trigger a trauma-specific emotional response, functioning as a visual cue for the recovery of repressed traumatic memories, and that the "interaction between mind and body" at times keeps the "past trauma 'alive." As Ogden et al. (2006) have shown, I have experienced "sensorimotor reactions and symptoms that 'tell the story' without words" (p. 3). ${ }^{5}$ The overwhelming fear in my stomach and the sensation of being strangled are "remnants of past trauma." My response when woken up while in a deep sleep to scream, feeling extreme fear and dread, and even starting to jump out a window for safety are "sensorimotor reactions"- what the American Psychiatric Association calls "exaggerated startle response[s]"- - that mean I am "not safe" (Ogden et al., 2006, p. 5). This resulted 
in my fear of the mundane: the dark, the nighttime, strangers, being alone, the sudden, unexpected movement of my analyst. As Terr states, "Traumatized children tend also to fear mundane times - the dark, strangers, looming objects, being alone" (Terr, 1991, p. 13).

Besides the inability to recover who tried to strangle me, I probably will never know how the history of sexual abuse existed in my family prior to my parents' generation, although I have suspicions. I always knew that my grandmother had committed suicide when my mother was 6 years old. My mother's story claimed that she jumped out of their apartment window in pre-Nazi Berlin. It was not until I was an adult that I learned from my cousin (who lives in Rio de Janiero), something later confirmed by my uncle, that my grandmother had taken pills at her father's gravesite; her body was found beside his tombstone. According to my mother and one uncle, my grandmother had a history of depression because she could not deal with her husband's string of affairs with other women. Another uncle attributed it to "female problems." I suspect that my grandmother's suicide resulted from her own incestual abuse, which my mother also may have experienced, for why else did she tell me that this is what little girls were expected to do?

Discussing the function of literature in relation to incest, Elizabeth Barnes notes that it "provides both a means for the displacement of traumatic experience onto myth, stories, and so forth" and "a means for its realization, through witnessing of trauma by listeners/readers," and, of course, viewers. Barnes continues, "Though historical evidence of an event may be in abundance, no real knowledge of it exists until the event is 'witnessed' - that is, until someone has become cognizant of it" (Gaines, 2002, p. 2). As Dori Laub elaborates, "The testimony of the trauma thus includes its [listener/ reader/viewer], who is, so to speak, the blank screen on which the event comes to be inscribed for the first time" (Laub, p. 57). Certainly, Dr. C. witnessed my traumatic memories as they unfolded like film stills with segments missing. When I first recovered the memory of my childhood sexual abuse, I could not remember who had entered my room at night to perform sexual acts on me. This memory was blocked until I viewed the At Home Project. I thus became the witness of my own traumatic experience through the viewing of representations, demonstrating the veracity of Ruth Leys's (2000) antimimetic theory of trauma. She argues that the subject remains the spectator of the traumatic event, which she represents to herself and others (Leys, 2000, p. 10). In this case, through this personal survivor testimony, I not only show how remembering and forgetting may be central to the recovery of trauma, but also that artworks can enable a victim to escape from the dialectical cycle of the two, arriving at memory, mourning, and recovery.

The At Home Project continues to provide me with an avenue to remember, accept, recover, and survive my sexual trauma. The work of art enabled me to understand more fully the aftereffects of incest and how it plays out in my life. More specifically, it has allowed me to follow more clearly the traces of these aftereffects of incest that manifest themselves through binge eating, depression, suicidal thoughts, self-hatred, sleep problems, shame, unremitting sadness, nightmares, and the pain in my neck. It also facilitates my externalization of an inner conflict that I have repressed.

The At Home Project evoked visceral responses that triggered repressed memories and brought me to a different understanding of myself and the art. Through psychoanalysis, viewing a Hollywood film and the At Home Project, and having a daughter and watching her develop in a trauma-free environment, I now remember, speak out, and share my story, ending the silence in the hope that my making meaning of my own trauma can assist others. ${ }^{6}$ I hope that my reinterpretation of artworks, taken from a personal and professional perspective, brings to light important issues about sexual trauma in our culture. I would also like my explanation of how a work of art can serve as a cue for the retrieval of lost memories to provide a model for understanding the power of art and the process of remembering.

\section{Acknowledgement}

The author would like to thank the fellows in Trauma Studies at the Robert Penn Warren Center of the Humanities and its executive director Mona Frederick for assisting me in understanding more clearly trauma theory and for providing encouragement for this personal memoir.

\section{Declaration of Conflicting Interests}

The author declared no conflicts of interest with respect to the authorship and/or publication of this article.

\section{Funding}

The author received no financial support for the research and/or authorship of this article.

\section{Notes}

1. I use the term recovery rather than heal based on Anderson and Hiersteiner's (2008) distinctions. They argue that to heal suggests that trauma and its effects no longer interfere with one's life and that child abuse is no longer a part of one's identity. Recovery suggests instead that "sexual abuse remains a part of who they are but no longer defines them" (pp. 417-418).

2. As Terr (1994, pp. 12-13) explains,

Memory retrieval . . . frequently requires a strong perceptual stimulus - a cue ... But the most powerful impetus for the return of traumatic remembrance is not mood or state but a very simple perception, or cue . . . It appears that vision is the strongest immediate stimulus to old lost memories. 
3. Terr (1994, p. 56) explains that "behaviors, especially if they are trauma-specific, confirm the gist of a memory. Symptoms and signs, plus their underlying memories, become lifelong motifs for people."

4. Sensorimotor psychotherapy "has developed body theory to guide the use of somatic interventions . . . working with body sensation and movement, "but excluding touch, which William Reich, Alexander Lowen, and Louis Pelletier follow.

5. Anderson and Hiersteiner (2008) address how a "self-narrative" assists in "making meaning of one's trauma" (p. 417).

\section{References}

American Psychiatric Association. (2000). The diagnostic and statistical manual of mental disorders (4th ed., Text revision). Washington, DC: Author.

Anderson, K. M., \& Hiersteiner, C. (2008). Recovering from childhood sexual abuse: Is a "storybook ending" possible? American Journal of Family Therapy, 36, 413-424.

Applefield, A. (1994). Beyond despair. New York: Fromm.

Chu, J. (1998). Rebuilding shattered lives: The responsible treatment of complex post-traumatic and dissociative disorders. New York: Wiley.

Gaines, E. (Ed.). (2002). Incest and the literary imagination. Gainesville: University Press of Florida.

Kaplan, E. A. (2005). Trauma culture: The politics of terror and loss in media and literature. New Brunswick, NJ: Rutgers University Press.

Laub, D. (1992). Bearing witness or the vissitudes of 1 istening In Felman, S. \& Laub, D. (Ed.), Testimony. Crises of Witnessing in Literature. Psychology, and History, 57.

Leys, R. (2000). Trauma: A genealogy. Chicago: University of Chicago Press.

McNally, R. J. (2003). Remembering trauma. Cambridge, MA: Belknap Press of Harvard University Press.

Nochlin, L. (1988). Why have there been no great women artists? In L. Nochlin (Ed.), Women, art, and power and other essays (pp. 145-178). Boulder, CO: Westview Press.
Ogden, P., Minton, K., \& Pain, C. (2006). Trauma and the body: A sensorimotor approach to psychotherapy. New York: W. W. Norton.

Pierce-Baker, C. (2006). Memoir and academics [Electronic version]. The Scholar and Feminist Online, 4.

Rabinowitz, P. J. (1994). Reader-response theory and criticism. In M. Groden \& M. Kreiswirth (Ed.), The Johns Hopkins guide to literary theory and criticism (p. 606). Baltimore: Johns Hopkins University Press.

Smith, S. D., Abou-Khalil, B., \& Zald, D. H. (2009). Posttraumatic stress disorder in a patient with no left amygdale. Manuscript submitted for publication.

Terr, L. C. (1991). Childhood traumas: An outline and overview. American Journal of Psychiatry, 148, 10-20.

Terr, L. C. (1994). Unchained memories: True stories of traumatic memories, lost and found. New York: Basic Books.

\section{Bio}

Vivien Green Fryd is professor of History of Art and chair at Vanderbilt University. She. i.s the author of Art and Empire: The Politic.5 of Ethnicity in the US Capitol, 1815-1 860 (Yale University Press, 1992; reprint Ohi.o University Press, 2001) and Art and the Crisis of Marriage: Georgia O'Kecftè and Edward Hopper (Chicago: I.Jniversity of Chicago Press. 2003). She has published numerous articles, most recently "The 'Ghosting' of Incest and Female Liasons in Harriet Hosmer's Beatrice Cenci," The Art Bulletin (June 2006), "Suzanne Lacy's Three Weeks in May: Performance Art as "Pxpanded Public Pedagogy," National Women 's Studies Association Journal 19 (special issue, Spring 2007), and "Bearing Witness to the Trauma of Slavery in Kara Walker's Eight Possible Beginnings," Continuum, special issue, "Trauma and History," 24, no- 1 (2010). She is currently writing a book manuscript, Representing and Peiforming Sexual Trauma in Second-Wave Feminist American Art, which investigates the intersection between sexual trauma and visual representations, arguing that works of art can act as testimonies that give voice to that which has been silenced. She was the Spence and Rebecca Webb Wilson Fellow at the Robert Penn Warren Center of the Humanities and director of its year-long seminar on Trauma Studies 2008-2009. 